\title{
BMJ Open Evaluating the intended and unintended consequences of opioid-prescribing interventions on primary care in British Columbia, Canada: protocol for a retrospective population-based cohort study
}

\author{
Dimitra Panagiotoglou (D) , ${ }^{1}$ Rita McCracken (D) , ${ }^{2}$ M Ruth Lavergne (D) , ${ }^{3,4}$ \\ Erin C Strumpf, ${ }^{1,5}$ Tara Gomes, ${ }^{6,7}$ Benedikt Fischer, ${ }^{8,9,10}$ Austyn Brackett, ${ }^{11}$ \\ Cheyenne Johnson, ${ }^{12,13}$ Perry Kendall ${ }^{12}$
}

To cite: Panagiotoglou D, McCracken R, Lavergne MR, et al. Evaluating the intended and unintended consequences of opioidprescribing interventions on primary care in British Columbia, Canada: protocol for a retrospective populationbased cohort study. BMJ Open 2020;10:e038724. doi:10.1136/ bmjopen-2020-038724

- Prepublication history for this paper is available online. To view these files, please visit the journal online (http://dx.doi org/10.1136/bmjopen-2020038724).

Received 25 March 2020 Revised 08 August 2020 Accepted 01 October 2020

D) Check for updates

(C) Author(s) (or their employer(s)) 2020. Re-use permitted under CC BY-NC. No commercial re-use. See rights and permissions. Published by BMJ.

For numbered affiliations see end of article.

\section{Correspondence to} Dr Dimitra Panagiotoglou; dimitra.panagiotoglou@mcgill. ca

\begin{abstract}
Introduction Between 2015 and 2018, there were over 40000 opioid-related overdose events and 4551 deaths among residents in British Columbia (BC). During this time the province mobilised a variety of policy levers to encourage physicians to expand access to opioid agonist treatment and the College of Physicians and Surgeons of British Columbia (CPSBC) released a practice standard establishing legally enforceable minimum thresholds of professional behaviour in the hopes of curtailing overdose events. Our goal is to conduct a comprehensive investigation of the intended and unintended consequences of these policy changes. Specifically, we aim to understand the effects of these measures on physician prescribing behaviours, identify physician characteristics associated with uptake of the new measures, and measure the effects of the policy changes on patients' access to quality primary care. Methods and analysis This is a population-level, retrospective cohort study of all BC primary care physicians who prescribed any opioid medication for opioid-use disorder or chronic non-cancer pain during

Strengths and limitations of this study

- This is a population-level study of all primary care physicians in British Columbia (approximately 6000, 1200 of which prescribed at least one opioid agonist treatment during the study period) and their patients (>4.8 million) over 6 years (2013-2018).

- By working with a comprehensive dataset, master drug lists and validated coding algorithms in a context where the majority of health services are provided at no cost and all prescription drug dispensations are recorded, we have minimised the potential for misclassification and capture as many patients as possible outside of a strict longitudinal cohort study.

- We use a combination of methods and explore the effects of the prescribing policies from both the physician and patient perspectives.

- We are unable to operationalise and evaluate adherence to all stipulations in the practice standard (ie, documentation of discussions for nonpharmaceutical alternatives or take-home naloxone kits, pill counts or urine tests).
\end{abstract} the study period, and their patients. The study period is 1 January 2013-31 December 2018, with a 1-year wash-in period (1 January 2012-31 December 2012) to exclude patients who initiated long-term opioid treatment prior to our study period or whose pain type (ie, 'chronic noncancer', 'acute', 'cancer or palliative', or 'other') cannot be confirmed. The project combines five administrative health datasets under the authority of the BC Ministry of Health, with the CPSBC's Physician Registry, BC Cancer Agency's Cancer Registry and Vital Statistics' Mortality data. We will create measures of prescribing concordance, access, continuity, and comprehensiveness to assess primary care delivery and quality at both the physician and patient level. We will use generalised estimating equations, interrupted time series, mixed effects models, and funnel plots to identify factors related to changes in prescribing and evaluate the impact of the changes to prescribing policies. Results will be reported using appropriate Enhancing the
QUAlity and Transparency Of health Research guidelines (eg, STrengthening the Reporting of OBservational studies in Epidemiology).

Ethics and dissemination This study has been approved by McGill University's Institutional Review Board (\#A11M55-19A), and the University of British Columbia's Research Ethics Board (\#H19-03537). We will disseminate results via a combination of open access peer-reviewed journal publications, conferences, lay summaries and OpEds.

\section{INTRODUCTION}

Between 2015 and 2018, there were over 40 000 opioid-related overdose events and 4551 deaths among residents in British Columbia 
(BC). ${ }^{1-4}$ The annual provincial overdose mortality rate rose from 4.7 per 100000 population in 2009 to 30.8 per 100000 population in 2018, and for Vancouver's Downtown Eastside exceeded 100 deaths per 100000 population. ${ }^{56}$ In an attempt to curtail the number of overdose events, the province launched new policies to encourage physicians and nurse practitioners to expand access to opioid agonist treatment (OAT) (OAT refers to a set of pharmacological antagonists (eg, methadone, buprenorphine or naltrexone) for addiction to opioids such as heroin, fentanyl, hydromorphone and oxycodone) including open listing buprenorphine/naloxone in the PharmaCare and First Nations Health Benefits programmes. ${ }^{7}$ Further, the province amended existing fees and introduced new ones to better compensate physicians who provide treatment for opioid-use disorder (OUD) ${ }^{89}$ Concurrently, the BC Centre on Substance Use (BCCSU) developed provincial guidelines and began offering comprehensive education and training for prescribers of OAT. ${ }^{10}$

Meanwhile, the College of Physicians and Surgeons of British Columbia (CPSBC) released the Safe Prescribing of Drugs with Potential for Misuse/Diversion practice standard (box 1) to 'prevent an increasing toll of prescription drug misuse and overdose deaths'. ${ }^{11}$ Recently renamed Safe Prescribing of Opioids and Sedatives, the CPSBC's practice standard evolved from the Centers for Disease Control and Prevention Guideline for Prescribing Opioids for Chronic Pain-USA, 2016, the College's Prescribing Principles (2012), and the National Opioid Use Guideline Group's Safe and Effective Use of Opioids for Chronic Non-Cancer Pain (2010). The practice standard reflects the findings that opioids compared with placebo modestly improve physical functioning and quality of life for people living with chronic non-cancer pain (lasting longer than 3 months); but that the risks of adverse health effects outweigh the benefits. ${ }^{12-14}$ Unlike its predecessors which recommended courses of action and allowed physicians to 'exercise reasonable discretion in their decision to act on guidance provided', the practice standard established legally enforceable minimum thresholds of professional behaviour. ${ }^{15}$ Non-compliant physicians can be disciplined or fined under the Health Professions Act, RSBC 1996, c.183 and College Bylaws. ${ }^{15} 16$

People with OUD are consistently marginalised and stigmatised from mainstream healthcare delivery systems, ${ }^{17} 18$ relying on expensive and fragmented care from emergency departments and walk-in clinics to address their acute and chronic medical conditions. ${ }^{19}{ }^{20}$ Policies aimed at expanding the provision of OAT may therefore have positive spillover effects beyond the benefits of the treatment itself. An expanded pool of prescribers, mostly family medicine physicians, may enable access to primary care services; improving continuity of care and reducing the use of walk-in clinics and emergency departments. ${ }^{21-24}$

Conversely, the CPSBC's practice standard may have inadvertently restricted access to quality primary care for patients with chronic non-cancer pain. ${ }^{25}$ Across Canada
Box 1 Safe prescribing of drugs with potential for misuse/

diversion practice standard, June 2016

\section{Physicians must:}

- Review patients' current medications before prescribing opioids, sedatives or stimulants.

- Base long-term treatment with medications with known risks, including opioids, sedatives and stimulants, on clinical diagnosis and objective evidence. Continuing to prescribe medication solely on the basis that they have been previously prescribed is not acceptable.

- Document discussion with patients that non-pharmacological therapy and non-opioid analgesics are preferred for chronic non-cancer pain, and that the potential benefit of long-term opioid treatment (LTOT) is modest and risk significant.

- Advise patients that LTOT is not indicated for certain medical conditions including headache disorders, fibromyalgia and axial low back pain.

- Always prescribe the lowest effective dosage of opioid medication. Doses $>50$ morphine milligram equivalents (MME) per day warrant careful reassessment and documentation. Doses $>90$ MME per day warrant substantive evidence of exceptional need and benefit. (This advice excludes treatment with methadone.)

- When treating patients with acute pain conditions, prescribe only immediate release opioids in quantities that the patient will need before community follow-up will be resumed (3-7 days is often adequate).

- When discharging patients from acute-care settings, or postoperatively, prescribe only the quantities of opioids, sedatives or stimulants that the patient will need before community follow-up will be resumed.

- Base decisions to prescribe long-term psychoactive medications, including LTOT, on well-documented, comprehensive initial assessments and frequent (at least every 3 months) reassessments. These assessments and reassessments must include documented history and physical examination of the patient. There must also be documentation that the patient has been screened regularly for the presence or emergence of mental health and substance-use disorders and risk factors, and advised about safety-sensitive occupational risks, child care responsibilities and driving.

- Document the offer of a take-home naloxone prescription to all patients who are at risk of respiratory depression as a consequence of receiving opioid medications.

- Document having directed and regularly reminded patients for whom they are prescribing LTOT to abstain from alcohol and non-prescription sedatives.

- Order at least annual random urine drug testing and/or random pill counts for all adult patients on long-term opioids, benzodiazepines, sedative hypnotics or stimulants.

\section{Further, physicians must not:}

- Prescribe benzodiazepines or sedative hypnotics to patients on LTOT, other than as a documented taper.

- Prescribe combinations of opioids with benzodiazepines and/or sedative hypnotics.

- Provide prescriptions allowing dispenses of opioids, sedatives and stimulants, which exceed a 3-month supply or 250 tablets, whichever is less.

- Initiate treatment with drugs with a high-risk profile such as methadone and fentanyl without relevant training and experience.

and the USA there is growing anecdotal evidence that opioid-prescribing guidelines have negatively affected people who could benefit from opioids. Incorrect interpretations of the standard can result in aggressive weaning without consent, cause debilitating pain and 
serious withdrawal symptoms, strain patient-physician relationships and increase risk of overdose for patients who self-medicate for pain relief. ${ }^{26-32}$

Our goal is to conduct a comprehensive investigation of the intended and unintended consequences of the changes to OAT prescribing and the CPSBC's practice standard for patients and primary care physicians in BC. To meet this objective, we will:

1. Examine the uptake of OAT prescribing and the adoption of the CPSBC's practice standard among primary care physicians based on the following research questions (RQs):

1.1 How do physicians who begin prescribing OAT between 2016 and 2018 differ from those who do not, and with providers already offering OAT prior to recent prescribing changes?

1.2 To what extent do physicians vary in adopting the CPSBC's practice standard?

1.3 What are the effects of the practice standard on prescribing patterns of long-term opioid treatment (LTOT)?

1.4 What physician characteristics are associated with ceasing prescription of controlled substances, and with terminating primary care for patients on LTOT?

2. Determine the effects of the changes to opioid prescribing on primary care for patients based on the following RQs:

2.1 What are the characteristics of patients who are newly prescribed OAT (2016-2018)?

2.2 What are the characteristics of patients who experience rapid tapering and/or termination with their primary care provider following the release of the CPSBC's practice standard?

2.3 Do patients who begin OAT experience changes in primary care access, continuity or comprehensiveness? 2.4 Do patients treated with LTOT experience changes in primary care access, continuity or comprehensiveness following implementation of the new practice standard?

\section{METHODS AND ANALYSIS}

This project is set to start September 2020 and end August 2024.

\section{Study setting}

BC is Canada's most western province, and has a population of approximately 4.8 million residents. There are over 1200 OAT prescribers ${ }^{33}$ among approximately 6000 primary care physicians and addiction specialists. ${ }^{34}$ The province provides single-payer coverage of inpatient and outpatient health services through its Medical Services Plan (MSP). Residents excluded from the insurance programme include newly landed immigrants and people covered under federal insurance programmes including refugees, asylum seekers, military personnel and First Nations' members (representing less than $4 \%$ of the population). ${ }^{35}$
In 2012, fentanyl was first detected in the illicit drug supply, and $4 \%$ of the province's 270 overdose deaths were fentanyl-related (illicit overdose events include indication of street drugs (controlled and illegal: heroin, cocaine, MDMA, methamphetamine, illicit fentanyl), and medications not prescribed to the decedent but obtained/purchased on the street, from unknown means, or where origin of drug not known). By 2018, fentanyl was detected in over $80 \%$ of the province's 1535 drug overdose deaths. ${ }^{36}$ Dr Perry Kendall, the provincial medical health officer at the time, declared the opioid overdose epidemic a public health emergency in April 2016. ${ }^{37}$ The declaration enabled the BC Centre for Disease Control, Ministry of Health, Regional Health Authorities, BC Coroner Services and related stakeholders to quickly expand surveillance efforts and adopt new harm reduction programmes (eg, overdose prevention sites, takehome naloxone programmes), treatment and recovery interventions. Meanwhile, the Ministry of Health and the College of Physicians focused on supply side interventions to prevent overdose deaths and reduce harms. ${ }^{37} \mathrm{~A}$ variety of studies are currently underway to evaluate the effects of these interventions.

\section{Data sources and linkages}

This project combines five administrative health datasets under the authority of the BC Ministry of Health, with the CPSBC's Physician Registry, BC Cancer Agency's Cancer Registry and Vital Statistics' Mortality data (table 1). Population Data BC, a multi-university data resource, will provide secure access to individual level, linked and de-identified data for our research purposes.

\section{Patient and public involvement}

As part of the project's development, we recruited a patient-partner with lived experience from the Patient Voices Network. Through a series of meetings, the patientpartner has informed the research aims of the project and outcome measures of interest. This patient-partner will remain an integral member of the team assisting in the interpretation of patient-level results and knowledge dissemination efforts. As this project uses secondary administrative data, no additional patients were recruited for the conduct of the study.

\section{Study design and study population}

This is a population-level, retrospective cohort study of all BC primary care physicians who prescribed any opioid medication for OUD or chronic non-cancer pain during the study period, and their patients. The study period is 1 January 2013-31 December 2018, with a 1-year wash-in period (1 January 2012-31 December 2012) to exclude patients who initiated LTOT before 2012 or whose pain type (ie, 'chronic non-cancer', 'acute', 'cancer or palliative', or 'other') cannot be confirmed (figure 1).

The cohort will include all primary care physicians and their patients using the CPSBC's Physician Registry and MSP billings. We will use PharmaNet data to identify all 


\begin{tabular}{|c|c|c|}
\hline Database & Description & Source \\
\hline PharmaNet & $\begin{array}{l}\text { All prescriptions dispensed } \\
\text { from community and hospital } \\
\text { outpatient pharmacies to } \\
\text { BC residents for home use, } \\
\text { irrespective of payer }\end{array}$ & $\mathrm{BC} \mathrm{MoH}$ \\
\hline Cancer Registry & $\begin{array}{l}\text { In } \mathrm{BC} \text {, cancer is a reportable } \\
\text { disease and the registry captures } \\
\text { all cancers diagnosed for } \mathrm{BC} \\
\text { residents and their treatment }\end{array}$ & $\begin{array}{l}\text { BC } \\
\text { Cancer } \\
\text { Agency }\end{array}$ \\
\hline Physician Registry & $\begin{array}{l}\text { Demographic information on } \\
\text { all registered and practicing } \\
\text { physicians including practice } \\
\text { status (active or retired), and } \\
\text { specialty }\end{array}$ & CPSBC \\
\hline $\begin{array}{l}\text { Patient Registry } \\
\text { File (MSP) }\end{array}$ & $\begin{array}{l}\text { Demographic data on all patients } \\
\text { covered by the provincial } \\
\text { insurance programme }\end{array}$ & $\mathrm{BC} \mathrm{MoH}$ \\
\hline $\begin{array}{l}\text { Physician Billing } \\
\text { (MSP) }\end{array}$ & $\begin{array}{l}\text { All inpatient and outpatient } \\
\text { fee-for-service physician } \\
\text { billing records; includes ICD-9 } \\
\text { diagnosis codes }\end{array}$ & $\mathrm{BC} \mathrm{MoH}$ \\
\hline $\begin{array}{l}\text { National } \\
\text { Ambulatory Care } \\
\text { Reporting System }\end{array}$ & $\begin{array}{l}\text { All ambulatory care visits to } \\
\text { hospitals, community and private } \\
\text { clinics; includes ICD-9 primary } \\
\text { diagnosis }\end{array}$ & $\mathrm{BC} \mathrm{MoH}$ \\
\hline $\begin{array}{l}\text { Discharge Abstract } \\
\text { Database }\end{array}$ & $\begin{array}{l}\text { All BC hospital discharge } \\
\text { records (inpatient and day } \\
\text { surgeries); including up to } 25 \\
\text { ICD-10 diagnostic codes and up } \\
\text { to } 25 \text { Canadian Classification of } \\
\text { Health Interventions procedure } \\
\text { codes }\end{array}$ & $\mathrm{BC} \mathrm{MoH}$ \\
\hline Mortality & $\begin{array}{l}\text { All deaths registered in the } \\
\text { province; includes ICD-10 } \\
\text { underlying cause of death and } \\
\text { record axis codes }\end{array}$ & $\begin{array}{l}\text { Vital } \\
\text { Statistics }\end{array}$ \\
\hline
\end{tabular}

BC, British Columbia; CPSBC, College of Physicians and Surgeons of British Columbia; ICD, International Classification of Diseases; MoH, Ministry of Health; MSP, Medical Services Plan.

physicians (including specialists) who prescribed any opioid during the study period so we can determine the physician who initiated each opioid prescription. For all patients, MSP, National Ambulatory Care Reporting System (NACRS) and Discharge Abstract Database (DAD) will provide complete health service use history during the wash-in and study periods; indicate the types of services the prescription initiating physician provides and enable us to control for patient-level comorbidities. The Cancer Registry and PharmaNet will allow us to identify and exclude patients being treated for cancer and palliative care. DAD and mortality data will be used to identify patient subpopulations who are disproportionately harmed by the changes. All records in the MSP, NACRS, DAD and PharmaNet files include de-identified

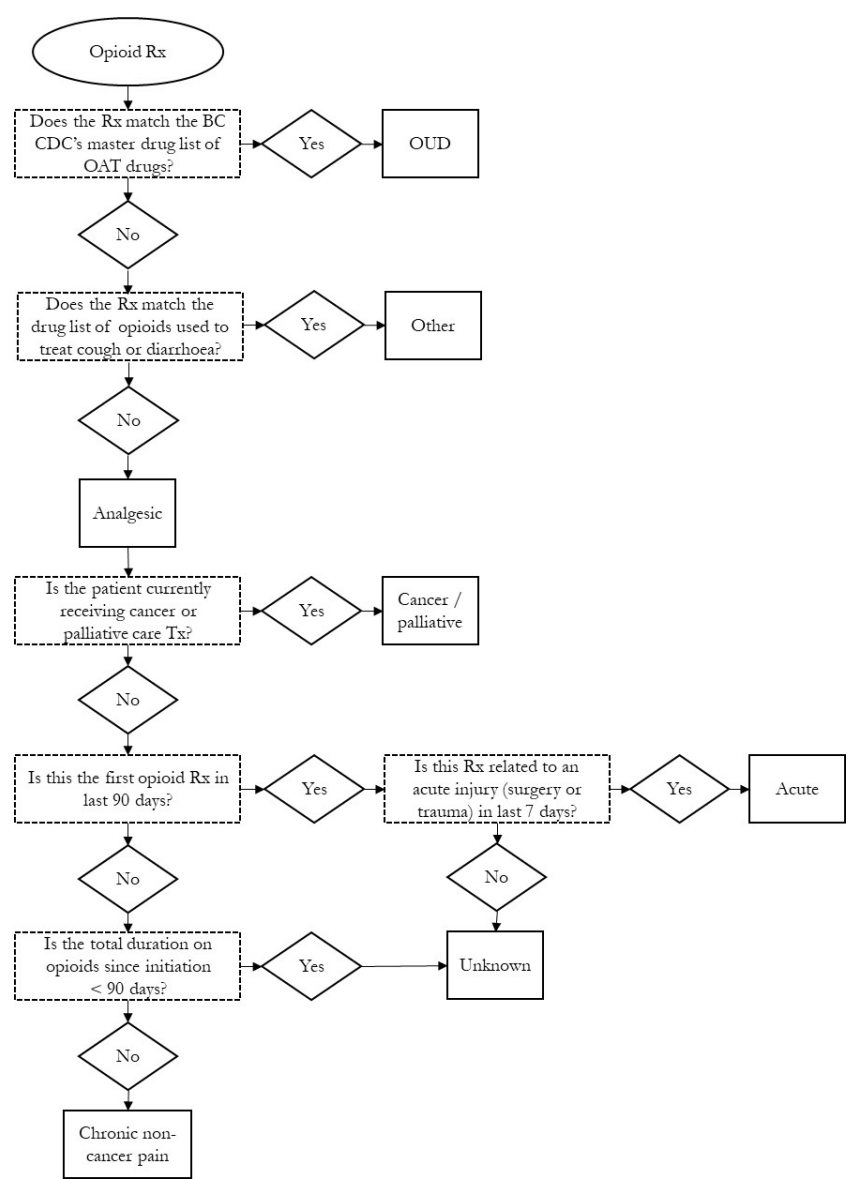

Figure 1 Primary use decision tree. BC CDC, British Columbia Centre for Disease Control; OAT, opioid agonist treatment; Rx, prescription; Tx, treatment.

physician and referring practitioner numbers for referral pattern purposes.

\section{Operationalised measures}

We will operationalise a series of variables using our linked dataset (tables 2 and 3).

\section{Analysis plan for each objective}

Data will be prepared using SAS (V.9.4) and statistical analyses will be performed using R (V.3.2.5). In general, missing and incomplete data will be excluded from analyses and the number of observations omitted from analyses due to missing data will be documented. If any imputation is used, the method and extent will be reported. We will report $p$ values $<0.05$ and $95 \%$ confidence intervals. Results will be reported using appropriate Enhancing the QUAlity and Transparency Of health Research guidelines (eg, STrengthening the Reporting of OBservational studies in Epidemiology).

Physicians' uptake of OAT prescribing and the adoption of the CPSBC's practice standard

To examine the differences between primary care physicians who begin prescribing OAT to patients with OUD and those who do not (RQ1.1), we will restrict our analysis to OAT-naive physicians (ie, never prescribed OAT 


\begin{tabular}{|c|c|c|c|c|c|}
\hline Variable & Type & Level & Definition & Frequency & Data source(s) \\
\hline $\begin{array}{l}\text { Primary } \\
\text { purpose }\end{array}$ & Categorical & Patient & $\begin{array}{l}\text { Classify each opioid prescription fill as 'chronic non-cancer', } \\
\text { 'acute', 'cancer/palliative', 'OAT', 'other' or 'unknown' using } \\
\text { the British Columbia (BC) Cancer Agency Cancer Registry, } \\
\text { PharmaCare's Plan B (residential) and Plan P (palliative care) } \\
\text { claims records, College of Pharmacists of BC's and Health } \\
\text { Quality Ontario's lists of non-analgesic formulations (ie, for } \\
\text { treatment of cough or diarrhoea), the BC CDC's master drug } \\
\text { list classification, existing validated coding algorithms and time } \\
\text { since prescription initiation } 62-64\end{array}$ & Per Rx & $\begin{array}{l}\text { BC Cancer Agency } \\
\text { Cancer Registry, } \\
\text { PharmaNet, } \\
\text { Physician Billing, } \\
\text { DAD, master drug } \\
\text { lists (College of } \\
\text { Pharmacists, HQ } \\
\text { Ontario, BC CDC) }\end{array}$ \\
\hline Daily dose & Continuous & Patient & $\begin{array}{l}\text { Convert prescriptions to daily morphine milligram equivalents } \\
\text { using the } \mathrm{BC} C \mathrm{CD} \text { drug classification list conversion factor } \\
\text { developed from WHO guidelines }\end{array}$ & Per Rx & PharmaNet \\
\hline
\end{tabular}

\begin{tabular}{|c|c|c|c|c|c|}
\hline Release & Categorical & Patient & $\begin{array}{l}\text { Distinguish between 'short-acting' and 'long-acting/extended } \\
\text { release formulations' using BC CDC drug list classification }{ }^{65}\end{array}$ & Per Rx & PharmaNet \\
\hline $\begin{array}{l}\text { Usual } \\
\text { prescriber of } \\
\text { care }\end{array}$ & Categorical & Patient & $\begin{array}{l}\text { Assigned as the primary care physician who initiated the } \\
\text { LTOT or OAT prescription. Where prescriptions were initiated } \\
\text { by specialists or in-hospital, or where patients have been } \\
\text { transferred between practices (eg, following physician }\end{array}$ & Per Rx & $\begin{array}{l}\text { PharmaNet, } \\
\text { Physician Billing, } \\
\text { Patient Registry, } \\
\text { DAD }\end{array}$ \\
\hline
\end{tabular}

retirement), the primary care physician that renews the prescription at least once is assigned usual prescriber of care.

For the purposes of a control group, usual prescriber will be assigned as the primary care physician who initiates or continues diabetes-specific pharmacotherapy (eg, metformin). ${ }^{66}$

Value: unique de-identified physician practice number

\begin{tabular}{|c|c|c|c|c|c|}
\hline \multirow[t]{2}{*}{$\begin{array}{l}\mathrm{Rx} \\
\text { concordance }\end{array}$} & Categorical & Patient & $\begin{array}{l}\text { For each LTOT prescription filled for chronic, non-cancer } \\
\text { pain, determine whether or not it is concordant with the } \\
\text { CPSBC's practice standard (figure 2). Non-concordant fills will } \\
\text { be dispensations contraindicated or where dosing exceeds } \\
\text { recommended levels. }\end{array}$ & Per Rx & $\begin{array}{l}\text { PharmaNet, } \\
\text { Physician Billing, } \\
\text { DAD }\end{array}$ \\
\hline & & & Values: binary (yes/no) & & \\
\hline \multirow[t]{2}{*}{$\begin{array}{l}\text { Controlled } \\
\text { substances } \\
\text { cessation }\end{array}$} & Categorical & Physician & $\begin{array}{l}\text { For physicians who ever prescribed a controlled substance (eg, } \\
\text { buprenorphine, hydromorphone), }{ }^{67} \text { we will distinguish physicians } \\
\text { who terminated any prescription abruptly for at least } 3 \text { months } \\
\text { from those who did not (excluding physicians who have retired, } \\
\text { died or moved; and prescriptions appropriately tapered over } \\
\text { time) }\end{array}$ & Per Rx & $\begin{array}{l}\text { PharmaNet, } \\
\text { Physician Registry }\end{array}$ \\
\hline & & & Values: binary (yes/no) & & \\
\hline $\begin{array}{l}\text { Treatment } \\
\text { termination }\end{array}$ & Categorical & Patient & $\begin{array}{l}\text { For patients on LTOT whose treatment was abruptly stopped or } \\
\text { rapidly tapered by their usual prescriber of care. Patients who } \\
\text { move, are safely tapered ( }<10 \% \text { dose difference week to week), } \\
\text { are overseen by a new physician with less than } 30 \text {-day gap } \\
\text { between prescription, or whose usual prescriber retired, moved } \\
\text { or died will be excluded. }\end{array}$ & Annual & $\begin{array}{l}\text { PharmaNet, } \\
\text { Physician Registry, } \\
\text { Patient Registry } \\
\text { File }\end{array}$ \\
\hline
\end{tabular}

CDC, Centre for Disease Control; CPSBC, College of Physicians and Surgeons of British Columbia; DAD, Discharge Abstract Database; HQ, health quality; LTOT, long-term opioid treatment; OAT, opioid agonist treatment; Rx, prescription.

during the 3-year wash-in period: 2012-2014, inclusive), and saw OAT-naive patients with indication of an OUD between 2015 and 2018, inclusive. This will allow us to examine the cohort of physicians who were susceptible to OAT expansion interventions. We will use generalised estimating equations (GEE) for logistic regression to identify physician-level characteristics (eg, age, sex, years since training completion, geography, practice type and prescribing history) associated with OAT prescribing. These non-parametric models allow us to account for the repeated measures and hierarchical structure of our data by specifying joint distribution in their random effects terms, and are well suited to identifying population average differences. ${ }^{38} 39$ We will repeat the analysis to compare physician characteristics associated with new OAT prescribing (ie, first prescription post-2015) compared with early adopters (ie, primary care physicians prescribing OAT pre-2015).

To understand the extent to which physicians vary in adopting the CPSBC's practice standard (RQ1.2), we will restrict analysis to physicians who prescribed LTOT between June 2014 and May 2016 and again during the effective period of the CPSBC's practice standard (June 2016-May 2018). We will use funnel plots to quantify the extent of deviation in prescription concordance (concordance prior to the implementation of the 
Table 3 Quality of primary care measures

\begin{tabular}{|c|c|c|c|c|c|}
\hline Variable & Type & Level & Definition & Frequency & Data source(s) \\
\hline \multirow[t]{2}{*}{$\begin{array}{l}\text { Access to primary } \\
\text { care }\end{array}$} & \multirow[t]{2}{*}{ Continuous } & \multirow[t]{2}{*}{ Patient } & $\begin{array}{l}\text { The proportion of all non-urgent (eg, Canadian Triage and } \\
\text { Acuity Scale of } 4 \text { or } 5 \text { ) ambulatory visits that are with a } \\
\text { primary care physician, in the preceding year, at the time of } \\
\text { each prescription. }\end{array}$ & \multirow[t]{2}{*}{ Per Rx } & \multirow[t]{2}{*}{$\begin{array}{l}\text { Patient Registry, } \\
\text { Physician Billing, } \\
\text { Physician Registry, } \\
\text { NACRS }\end{array}$} \\
\hline & & & Values: numerical, bound between 0 and 1 & & \\
\hline \multirow[t]{2}{*}{ Continuity of care } & \multirow[t]{2}{*}{ Continuous } & \multirow[t]{2}{*}{ Patient } & $\begin{array}{l}\text { Number of contacts with the usual prescriber of care, } \\
\text { divided by the number of all ambulatory contacts, in the } \\
\text { preceding year, at the time of each prescription. }\end{array}$ & \multirow[t]{2}{*}{ Per Rx } & \multirow{2}{*}{$\begin{array}{l}\text { Patient Registry, } \\
\text { Physician Billing, } \\
\text { Physician Registry, } \\
\text { NACRS }\end{array}$} \\
\hline & & & Values: numerical, bound between 0 and 1 & & \\
\hline
\end{tabular}

\begin{tabular}{|c|c|c|c|c|c|}
\hline \multirow[t]{2}{*}{ Practice type } & Categorical & Physician & $\begin{array}{l}\text { We will apply Schultz and Glazier's approach }{ }^{68} \text { to create an } \\
\text { empirical threshold for primary care comprehensiveness } \\
\text { and classify each primary care physician by the number of } \\
\text { distinct activity areas they bill. }\end{array}$ & Per Rx & $\begin{array}{l}\text { Physician Billing, } \\
\text { Physician Registry }\end{array}$ \\
\hline & & & $\begin{array}{l}\text { Comprehensive practice }=\# \text { activity areas } \geq \text { empirical } \\
\text { threshold }\end{array}$ & & \\
\hline
\end{tabular}

NACRS, National Ambulatory Care Reporting System ; Rx, prescription.

CPSBC's practice standard (June 2014-May 2016) will be an artificial measure used to identify physician outliers susceptible to the effects of the practice standard postimplementation) (figure 2) at the physician-level before and after the implementation of the practice standard. Physicians whose observed proportion of non-concordant prescriptions remain above the upper $95 \%$ control limits of the expected proportion of non-concordant fills (given the number of prescriptions they prescribed, and controlling for patient and geographical differences) following the implementation of the standard, will be compared with primary care peers whose prescribing becomes concordant. We will use mixed-effects models to identify physician characteristics associated with non-concordance.

To estimate the effects of the practice standard (implemented June 2016) on usual prescribers of care's LTOT prescriptions (RQ1.3), we will use interrupted time series (ITS) analysis. ITS is a quasi-experimental study design that estimates the effects of service or policy interventions before and after implementation in contexts where randomised controlled trials are not feasible or ethical. ${ }^{40}$ The advantage of this before-after comparison with a single population is that selection bias and confounding due to between-group differences are limited; and within-group characteristics that change slowly over time (eg, physician characteristics), secular changes, random fluctuations from one time point to the next and regression to the mean are also controlled. ${ }^{42}$ The primary assumption for ITS is that without the intervention (here the introduction of the CPSBC's practice standard), the observed pre-intervention outcome trends would continue unchanged into the post-intervention period. This assumption is supported by Crabtree $e t a l \mathrm{~s}^{43}$ work which found no change in trends of defined daily dose of opioids prescribed pre-implementation versus post-implementation of the practice standard. Additionally, to our knowledge there were no other interventions that would affect physician prescribing of LTOT implemented during our study period. Using this method, we will look at the effects of the practice standard on the number of LTOT prescriptions filled with: (a) a daily dose greater than 90 morphine milligram equivalents; (b) a benzodiazepine co-prescription; and (c) a supply that exceeds 3 months or 250 tablets (whichever is less). We will also look at (d) the number of physicians who terminate any controlled substance and (e) the number of LTOT prescriptions terminated. We selected these outcomes because the CPSBC's primary aim for establishing the practice standard was to reduce prescription drug misuse. However, we would also like to quantify the extent of inappropriate treatment cessation, as suggested by mounting anecdotal evidence. Given the potential rarity of the outcomes, we will aggregate counts to eight quarterly periods pre-implementation and postimplementation (pre-intervention: June 2014-May 2016; post-intervention: June 2016-May 2018). We will use the two-sided Durbin-Watson test, plot of residuals, and autocorrelation plots to identify and adjust for autocorrelation and moving averages where necessary. We will test the hypothesis that the practice standard had no effect on these outcomes using ordinary least squares and segmented regression.

Lastly, we will use GEE for logistic regression, and GEE for Poisson or negative binomial distribution to identify physician characteristics associated with any controlled 


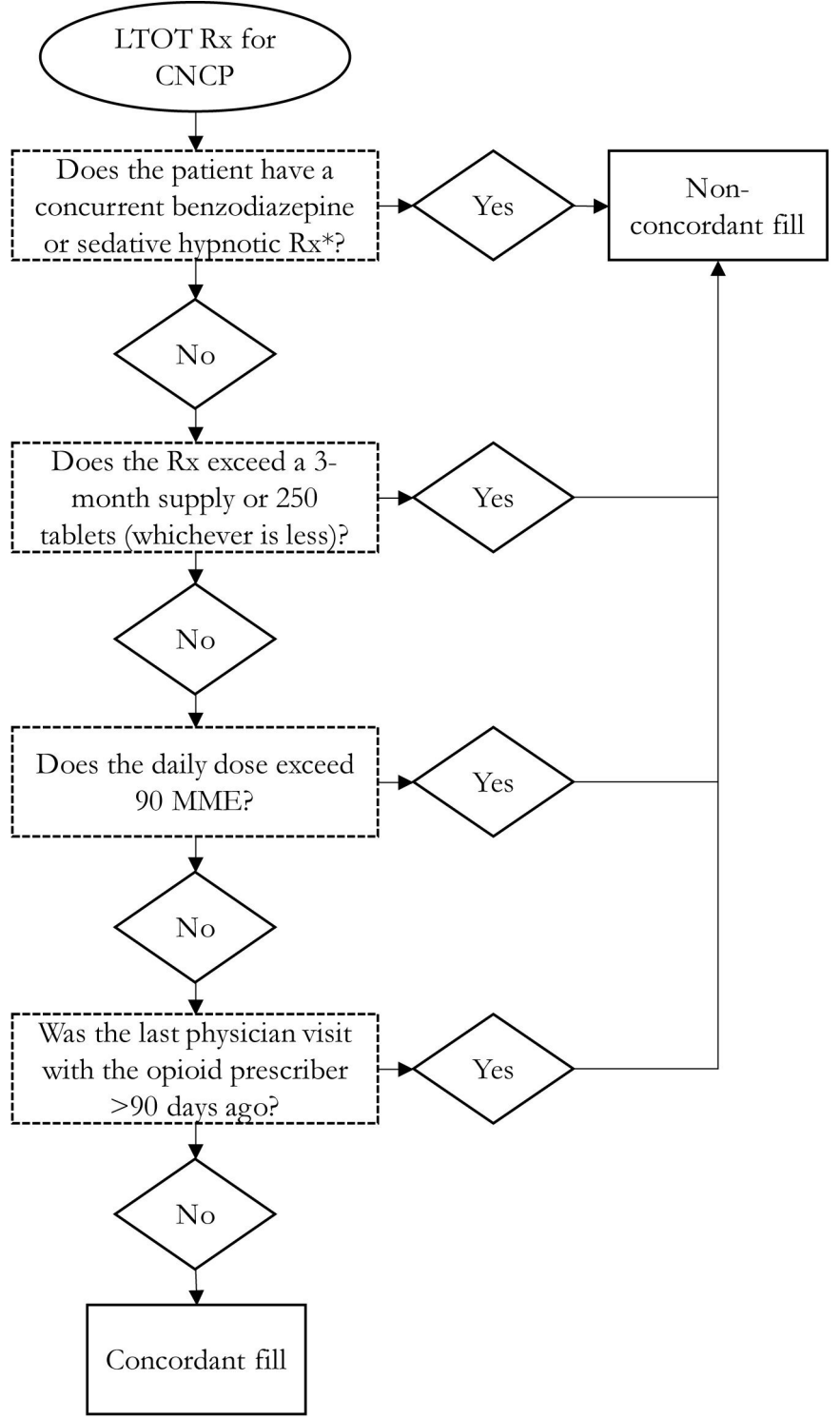

Figure 2 Long-term opioid treatment (LTOT) concordant fill decision tree. *Excluding benzodiazepine and sedative hypnotic tapers. CNCP, chronic non-cancer pain; MME, morphine milligram equivalents; Rx, prescription.

substances cessation, and with counts of treatment termination between 2016 and 2018, respectively (RQ1.4). Negative binomial models are similar to Poisson models with the exception that the mean and variance of the count data do not have to be the same. These models include an additional parameter to handle overdispersion in the data, and are well suited for zero inflation and unobserved heterogeneity in the data. ${ }^{44} 45$ To determine which of the two model types is best suited to the data, we will use Pearson $\mathrm{X}^{2}$ dispersion statistics and residual plots. $^{45} 46$

\section{Effects of the changes to opioid prescribing on primary care for patients}

We will use GEE for logistic regression to identify patientlevel characteristics (eg, age, sex, geography, comorbidities, contraindications) associated with OAT initiation between
2015 and 2018 among OAT-naive patients (no OAT prescription filled between 2012 and 2014, inclusive) with indication of OUD (RQ 2.1). For patients on LTOT as of June 2016, we will use GEE to identify patient-level characteristics associated with inappropriate treatment termination (including rapid tapering) and regression models to estimate risk of mortality (RQ2.2).

For RQ 2.3, we will use a variety of multiple linear (or linearised, where appropriate) regression models to measure the population-level association between expanded provision of OAT defined as the number of primary care physicians newly prescribing OAT as of 2015 (OAT prescribing naive 2012-2014) and changes to patients' access, continuity and comprehensiveness of primary care (independently), while controlling for patient-level characteristics (eg, age, sex, geography, indication of OUD, comorbidities and contraindications). Models will include a lag for the potential delayed effects between expanded provision of OAT and our outcomes. Lags between the number of physicians prescribing OAT and primary care outcomes will be estimated using the weighted cumulative approach ${ }^{4-49}$ and informed with expert input from our knowledge users/ stakeholders. ${ }^{50} 51$ We anticipate at least a 1-year lag between expanded OAT provision and changes in access, continuity and comprehensiveness of care given how these measures will be constructed.

To measure the effects of the practice standard on patients' access, continuity and comprehensiveness of primary care (RQ2.4), we will use controlled ITS analysis. This modified method allows us to account for time-varying confounders that may have influenced the delivery of primary care. Patients on LTOT just before the implementation of the practice standard will be matched with patients with diabetes not on opioids for pain management (eg, for neuropathic pain $)^{52}$ or OAT whose pharmacotherapy is overseen by the same physician, and on age, sex, Charlson Comorbidity Index and treatment initiation month. Patients with diabetes were selected as our negative control group because:

1. The majority of diabetes care is provided in primary care settings.

2. There were no contemporaneous policies affecting diabetes pharmacotherapy prescribing behaviours during the study period.

3. The opioid-prescribing standard is not expected to affect diabetes pharmacotherapy prescriptions.

4. There are clear practice guidelines for physicians treating patients with diabetes, including frequency of physician oversight, which are similar to the guidelines for patients on LTOT. ${ }^{53}$

5. Prescription disruptions (eg, termination, change in prescriber) are unusual for this patient population.

We will use 24 monthly intervals pre-implementation and post-implementation for a total of 48 time periods between June 2014 and May 2018 (inclusive). At each interval, the outcome measure will be assessed for each patient dispensed a prescription during that month (LTOT for exposed, diabetes drug for matched controls). We will test our hypothesis of no change in access, continuity or comprehensiveness 
of care using ordinary least squares and segmented regression, by fitting the following regression model, per outcome:

Outcome $_{\mathrm{jkt}}=\beta_{0}+\beta_{1}$ time $_{\mathrm{t}}+\beta_{2}$ group $_{\mathrm{k}}+\beta_{3}$ group $_{\mathrm{k}}$ time $_{\mathrm{t}}$

$$
\begin{aligned}
& +\beta_{4} \text { level }_{\mathrm{jt}}+\beta_{5} \text { trend }_{\mathrm{jt}}+\beta_{6} \text { level }_{\mathrm{jt}} \text { group }_{\mathrm{k}} \\
& +\beta_{7} \text { trend }_{\mathrm{jt}} \text { group }_{\mathrm{k}}+\varepsilon_{\mathrm{jkt}}
\end{aligned}
$$

where $j$ is the intervention, $t$ is the study time in monthly intervals pre-intervention (negative time) and postintervention (positive time), and $k$ distinguishes between intervention and control group. Significant values for coefficients $\beta_{6}$ and $\beta_{7}$ will indicate an effect of the practice standard on patients' access, continuity and comprehensiveness of primary care after accounting for level and trend changes among controls with diabetes.

\section{ETHICS AND DISSEMINATION}

This study has been approved by McGill University's Institutional Review Board (\#A11-M55-19A), and the University of British Columbia's Research Ethics Board (\#H19-03537).

All data used in this project will be linked using de-identified personal health numbers or physician practice numbers. The data will be stored in Population Data BC's Secure Research Environment, a central server for data storage and analysis, including encrypted backups, software and other services to ensure compliance with data access requirements. ${ }^{54}$ All members of the research team who will have access to the data have had the necessary tricouncil privacy training and will complete privacy training provided by Population Data BC. Study results will be screened by data stewards prior to publication to ensure privacy and confidentiality requirements are maintained, there is no gross misuse of the data and data are appropriately referenced. Linked data will remain within Population Data BC's Red Zone (terminals with no external connection) for up to 7 years after project completion before being destroyed by authorised data personnel.

\section{DISCUSSION}

Our objective is to evaluate the effects of interventions aimed to improve access to OAT and limit overprescribing of opioid analgesics on physician prescribing behaviour and patient access to comprehensive primary care. Given the potential for patient harm, it is important to understand the effects of the interventions to prevent over/ underprescribing of opioids, and to mitigate the effects of exacerbating or introducing new inequities in access to healthcare. We will use a variety of health service delivery outcomes and address limitations of existing research. Results from aim 1 will be useful for isolating the effects of the interventions on physician prescribing behaviour, and to identify physician characteristics associated with high-error prescribing in light of the new standard. Results from aim 2 will estimate the effects of the interventions on patients' recent primary care experiences; and enable policy makers and physicians to identify potential subgroups harmed by the recent changes in prescribing. Together, these results will provide invaluable information on the effects of recent opioid-prescribing policies at both the patient and prescriber level, and equip policymakers and regulatory colleges with the much-needed information to understand the intended and unintended consequences of opioid-prescribing interventions to finetune their policies.

The primary challenge of this project relates to the use of administrative health data to create quantifiable measures of access, continuity and comprehensiveness of care. In settings without comprehensive records of service use or where access to services and treatment is restricted, such methods can lead to under-ascertainment and estimation of key patient groups (eg, people with OUD) and undercounting primary care service use/provision..$^{55}$ For example, reliance on administrative data to accurately identify patient health needs (eg, opioid use disorder, chronic pain) may lead to misclassification. However, by working with the comprehensive dataset described above in a context where the majority of health services are provided at no cost, and by applying modern surveillance methods, we minimise the potential for misclassification and capture as many patients as possible outside of a strict longitudinal cohort study. ${ }^{56}$ Of note, while most provinces (eg, Quebec) lack access to complete drug dispensation records for their populations, $\mathrm{BC}$ is unique in that it includes all outpatient prescription fills for all residents, irrespective of payer, within PharmaNet's data file. These complete records, along with the BC Cancer Agency's Cancer Registry enable the cross-validation of patient pain type identified using algorithms which rely on inpatient and outpatient records only, and allow us to work around the issue of inadequate specificity in International Classification of Diseases coding described elsewhere. Further, recognising the limitations of working with administrative data, we have intentionally recruited primary care physicians, members of the BCCSU and CPSBC, and a patient-partner living with chronic pain in $\mathrm{BC}$ to inform all stages of the project including the operationalisation of performance measures, their analysis and the interpretation of results. For all health system performance measures, we will also conduct extensive sensitivity analyses.

Knowledge translation is integrated throughout the proposed study. Our team includes a primary care provider in active clinical practice, experts in substance-use treatment, policymakers and a patient with pertinent lived experience. The inclusion of diverse stakeholders within the project team has helped to confirm relevance of research aims and refine specific research questions. As the project progresses, we will meet with stakeholder groups to share interim findings and identify emergent policy areas where information from our project may inform decision-making. In addition to communicating results of research to stakeholders and policymakers, and through traditional academic channels (publications and conference presentations), we will also work to ensure 
end-of-grant research findings are accessible to people prescribed opioids in BC and to the public. We will disseminate results via a combination of open access peerreviewed publications in high-impact journals, conferences, lay summaries, OpEds and ongoing meetings with our stakeholders/knowledge users.

The overdose epidemic in $\mathrm{BC}$ is unique to that observed elsewhere in North America. In the USA, the opioid epidemic is described as a triple wave of overdose deaths starting with prescription opioids, followed by heroin, and more recently, fentanyl. ${ }^{57} 58$ Other regions in Canada demonstrate a similar epidemiological transition from prescription opioids to illicit substances. For $\mathrm{BC}$, contamination of the illicit drug supply seems to have driven the epidemic since the beginning. ${ }^{59}$ Although the underlying drivers of BC's overdose epidemic differ from those described in other parts of Canada and the USA, many of the responses to the epidemic parallel those observed elsewhere. The removal of the federal section 56 exemption from the Controlled Drugs and Substances Act for physicians to prescribe methadone, and subsequent provincial requirements for buprenorphine, along with coverage on public insurance programmes, expanded access to OAT for residents in Alberta, Ontario and Quebec. $^{60}{ }^{61}$ Similarly, while enforceable practice standards for the prescribing of opioid analgesics have not been implemented in other jurisdictions, provinces and states are struggling with purported effects of changes in prescribing guidelines. Given these response similarities, we expect findings will be of international relevance.

\section{Author affiliations}

${ }^{1}$ Department of Epidemiology, Biostatistics and Occupational Health, McGill University, Montreal, Québec, Canada

${ }^{2}$ Department of Family Practice, University of British Columbia Faculty of Medicine, Vancouver, British Columbia, Canada

${ }^{3}$ Centre for Applied Research in Mental Health and Addiction, Simon Fraser University, Burnaby, British Columbia, Canada

${ }^{4}$ Faculty of Health Sciences, Simon Fraser University, Burnaby, British Columbia, Canada

${ }^{5}$ Department of Economics, McGill University, Montreal, Québec, Canada

${ }^{6} \mathrm{Li}$ Ka Shing Knowledge Institute, St. Michael's Hospital, Toronto, Ontario, Canada

${ }^{7}$ Institute for Clinical Evaluative Sciences, University of Toronto, Toronto, Ontario,

Canada

${ }^{8}$ Faculty of Medical and Health Sciences, The University of Auckland, Auckland, New Zealand

${ }^{9}$ Institute for Mental Health Policy Research, Centre for Addiction and Mental, University of Toronto, Toronto, Ontario, Canada

${ }^{10}$ Department of Psychiatry, University of Toronto, Toronto, Ontario, Canada

${ }^{11}$ Patient Voices Network, Vancouver, British Columbia, Canada

${ }^{12}$ British Columbia Centre on Substance Use, Vancouver, British Columbia, Canada

${ }^{13}$ School of Nursing, University of British Columbia, Vancouver, British Columbia, Canada

\section{Twitter Rita McCracken @DrRitaMc}

Contributors DP and RM are the co-principal Investigators of the study. DP, RM and MRL conceived the study and overall design, with critical revisions from TG, $\mathrm{ECS}, \mathrm{BF}, \mathrm{AB}, \mathrm{CJ}$ and PK. All coauthors developed the analysis plan, with specific methodology input from TG and ECS. DP drafted the manuscript. All authors provided feedback on the manuscript, approved the final version to be published and agree to be accountable to all aspects of the work ensuring the project's accuracy and integrity.
Funding This proposal is currently under review for funding. To date, this research has received no specific grant from any funding agency in the public, commercial or not-for-profit sectors. It is supported by new hire start-up funds from McGill University.

Competing interests None declared.

Patient and public involvement Patients and/or the public were involved in the design, or conduct, or reporting, or dissemination plans of this research. Refer to the Methods section for further details.

Patient consent for publication Not required.

Provenance and peer review Not commissioned; externally peer reviewed.

Open access This is an open access article distributed in accordance with the Creative Commons Attribution Non Commercial (CC BY-NC 4.0) license, which permits others to distribute, remix, adapt, build upon this work non-commercially, and license their derivative works on different terms, provided the original work is properly cited, appropriate credit is given, any changes made indicated, and the use is non-commercial. See: http://creativecommons.org/licenses/by-nc/4.0/.

\section{ORCID iDs}

Dimitra Panagiotoglou http://orcid.org/0000-0002-6175-3634

Rita McCracken http://orcid.org/0000-0002-2962-0364

M Ruth Lavergne http://orcid.org/0000-0002-4205-4600

\section{REFERENCES}

1 Special Advisory Committee on the Epidemic of Opioid Overdoses. National report: apparent opioid-related deaths in Canada (January 2016 to December 2018). Ottawa: Public Health Agency of Canada, 2019.

2 Belzak L, Halverson J. The opioid crisis in Canada: a national perspective. Health Promot Chronic Dis Prev Can 2018;38:224-33.

3 Ye X, Sutherland J, Henry B, et al. At-a-glance - impact of drug overdose-related deaths on life expectancy at birth in British Columbia. Health Promot Chronic Dis Prev Can 2018;38:248-51.

4 Health P. Chronic disease prevention in Canada editorial. correction: at-a-glance - Impact of drug overdose-related deaths on life expectancy at birth in British Columbia. Health Promot Chronic Dis Prev Can 2019;39:64.

5 Vancouver Police Department. The opioid crisis: the need for treatment on demand. Vancouver Police Department, 2017.

6 Vancouver Coastal Health. Response to the opioid overdose crisis in Vancouver coastal health. Vancouver, BC: Vancouver Coastal Health, 2019.

7 Adams Eet al. A guideline for the clinical management: opioid use disorder. Vancouver, BC: BC Centre for Substance Use, 2017.

8 Dr. Bill. 5'addiction medicine fee codes' available in BC, 2018.

9 Doctors of BC. New fees, updated guidelines support treatment of opioid use disorder. Doctors of BC, 2018.

10 British Columbia Centre on Substance Use. Provincial opioid addiction treatment support program. Vancouver, BC: British Columbia Centre on Substance Use, 2016.

11 College of Physicians and Surgeons of British Columbia. Safe prescribing of drugs with potential for Misuse/Diversion. College of Physicians and Surgeons BC, 2016.

12 Colvin LA, Bull F, Hales TG. Perioperative opioid analgesia-when is enough too much? A review of opioid-induced tolerance and hyperalgesia. Lancet 2019;393:1558-68.

13 Busse JWet al. Opioids for chronic noncancer pain: a systematic review and meta-analysis opioids for chronic noncancer pain. JAMA 2018;320:2448-60.

14 Chou R, Deyo R, Devine B, et al. The effectiveness and risks of long-term opioid treatment of chronic pain. Evid Rep Technol Assess 2014:1-219.

15 Oetter HM. Clarification from the College of physicians and surgeons of bc on commentary about limitations of the CDC guideline for prescribing opioids. CMAJ 2017;189:E508.

16 Health Professions Act. [RSBC 1996] Chapter 183. Victoria, BC, 2019.

17 Pollack HA, Khoshnood K, Blankenship KM, et al. The impact of needle exchange-based health services on emergency department use. J Gen Intern Med 2002;17:341-8.

18 Wang L, Panagiotoglou D, Min JE, et al. Inability to access health and social services associated with mental health among people who inject drugs in a Canadian setting. Drug Alcohol Depend 2016;168:22-9. 
19 French MT, McGeary KA, Chitwood DD, et al. Chronic illicit drug use, health services utilization and the cost of medical care. Soc Sci Med 2000;50:1703-13.

20 Stein MD, Anderson B. Injection frequency mediates health service use among persons with a history of drug injection. Drug A/cohol Depend 2003;70:159-68.

21 Schwarz R, Zelenev A, Bruce RD, et al. Retention on buprenorphine treatment reduces emergency department utilization, but not hospitalization, among treatment-seeking patients with opioid dependence. J Subst Abuse Treat 2012;43:451-7.

22 Friedmann PD, Hendrickson JC, Gerstein DR, et al. Do mechanisms that link addiction treatment patients to primary care influence subsequent utilization of emergency and hospital care? Med Care 2006;44:8-15.

23 Laine C, Lin Y-T, Hauck WW, et al. Availability of medical care services in drug treatment clinics associated with lower repeated emergency department use. Med Care 2005;43:985-95.

24 Spithoff S, Kiran T, Khuu W, et al. Quality of primary care among individuals receiving treatment for opioid use disorder. Can Fam Physician 2019;65:343-51.

25 Volkow ND, McLellan AT. Opioid abuse in chronic painmisconceptions and mitigation strategies. $N$ Engl J Med 2016;374:1253-63.

26 Kroenke K, Alford DP, Argoff C, et al. Challenges with implementing the centers for disease control and prevention opioid guideline: a consensus panel report. Pain Med 2019;20:724-35.

27 Voon P, Callon C, Nguyen P, et al. Denial of prescription analgesia among people who inject drugs in a Canadian setting. Drug A/cohol Rev 2015;34:221-8.

28 Busse JW, Craigie S, Juurlink DN, et al. Guideline for opioid therapy and chronic noncancer pain. CMAJ 2017;189:E659-66.

29 Antoniou T, Ala-Leppilampi K, Shearer D, et al. 'Like being put on an ice floe and shoved away': a qualitative study of the impacts of opioid-related policy changes on people who take opioids. Int J Drug Policy 2019;66:15-22.

30 Dassieu L, Kaboré J-L, Choinière M, et al. Chronic pain management among people who use drugs: a health policy challenge in the context of the opioid crisis. Int J Drug Policy 2019;71:150-6.

31 Darnall BD, Juurlink D, Kerns RD, et al. International Stakeholder community of pain experts and leaders call for an urgent action on forced opioid tapering. Pain Medicine 2019;20:429-33.

32 Lupick T. Opioid refugees: How the fentanyl crisis led to a backlash against doctors that's leaving people in pain. In: The georgia straight. Vancouver, BC, 2018.

33 BC Centre for Disease Control. Overdose response indicators. In: Data \& reports. Vancouver, BC: BC Centre for Disease Control, 2019.

34 Hedden L, Barer ML, McGrail K, et al. In British Columbia, the supply of primary care physicians Grew, but their rate of clinical activity declined. Health Aff 2017;36:1904-11.

35 Morrow RL, Bassett K, Wright JM, et al. Influence of opioid prescribing standards on drug use among patients with long-term opioid use: a longitudinal cohort study. CMAJ Open 2019;7:E484-91.

36 BC Coroners Service. Illicit drug overdose deaths in bc: findings of coroners' investigations. Ministry of Public Safety and Solicitor General, 2018.

37 BC Centre for Disease Control. Public health emergency in BC. In Stories. Vancouver, BC: BC Centre for Disease Control, 2017.

38 Gebregziabher M, Zhao Y, Dismuke CE, et al. Joint modeling of multiple longitudinal cost outcomes using multivariate generalized linear mixed models. Health Serv Outcomes Res Methodol 2013;13:39-57.

39 Hubbard AE, Ahern J, Fleischer NL, et al. To GEE or not to GEE: comparing population average and mixed models for estimating the associations between neighborhood risk factors and health. Epidemiology 2010;21:467-74.

40 Cook TD. Quasi-experimentation: design analysis issues for field settings. Boston, MA: Houghton Mifflin Company, 1979.

41 Zhang F, Wagner AK, Ross-Degnan D. Simulation-based power calculation for designing interrupted time series analyses of health policy interventions. J Clin Epidemiol 2011;64:1252-61.

42 Lopez Bernal J, Cummins S, Gasparrini A. The use of controls in interrupted time series studies of public health interventions. Int $J$ Epidemiol 2018;47:2082-93.
43 Crabtree A, Rose C, Chong M, et al. Effects of the new prescribing standards in British Columbia on consumption of opioids and benzodiazepines and z drugs. Can Fam Physician 2019;65:e231-7.

44 Pedan A. Analysis of count data using the SAS system. SAS Institute Statistics, Data analysis, and data mining.

45 Liu W, Cela J. Count Data in SAS. SAS Institute statistics and data analysis 2008.

46 Meyer J. Poisson or negative binomial? Using count model diagnostics to select model. In the analysis factor, 2018.

47 Sylvestre M-P, Abrahamowicz M. Flexible modeling of the cumulative effects of time-dependent exposures on the hazard. Stat Med 2009;28:3437-53.

48 Danieli C, Abrahamowicz M. Competing risks modeling of cumulative effects of time-varying drug exposures. Stat Methods Med Res 2019;28:248-62

49 Xiao Y, Abrahamowicz M, Moodie EEM, et al. Flexible marginal structural models for estimating the cumulative effect of a timedependent treatment on the hazard: reassessing the cardiovascular risks of didanosine treatment in the Swiss HIV cohort study. J Am Stat Assoc 2014;109:455-64.

50 Soyiri IN, Reidpath DD, Sarran C. Forecasting asthma-related hospital admissions in London using negative binomial models. Chron Respir Dis 2013;10:85-94.

51 Briët OJT, Amerasinghe PH, Vounatsou P. Generalized seasonal autoregressive integrated moving average models for count data with application to malaria time series with low case numbers. PLoS One 2013;8:e65761.

52 Mu A, Weinberg E, Moulin DE, et al. Pharmacologic management of chronic neuropathic pain: review of the Canadian pain Society consensus statement. Can Fam Physician 2017;63:844-52.

53 Diabetes Canada Clinical Practice Guidelines Expert Committee. Diabetes Canada 2018 clinical practice guidelines for the prevention and management of diabetes in Canada. Can J Diabetes 2018:42:S1-325.

54 PopulationDataBC. Data access, 2018. Available: https://www. popdata.bc.ca/dataaccess [Accessed 25 Oct 2018].

55 Unick GJ, Rosenblum D, Mars S, et al. Intertwined epidemics: national demographic trends in hospitalizations for heroin- and opioid-related overdoses, 1993-2009. PLoS One 2013;8:e54496.

56 Haut ER, Pronovost PJ, Schneider EB. Limitations of administrative databases. JAMA 2012;307:2589-90.

57 Ciccarone D. The triple wave epidemic: supply and demand drivers of the US opioid overdose crisis. Int J Drug Policy 2019;71:183-8.

58 Schuchat A, Houry D, Guy GP., Jr. New data on opioid use and prescribing in the United StatesNew data on opioid use and prescribing, 2006-2015. JAMA 2017;318:425-6.

59 British Columbia Coroners Service. Illicit drug toxicity deaths in BC January 1, 2010-June 30, 2020. Victoria, BC: BC Coroners Service, 2020.

60 Régie de l'assurance maladie du Québec. Prescription drug insurance, 2018.

61 Régie de l'assurance maladie du Québec. List of medications, 2018.

62 Lacasse A, Ware MA, Dorais M, et al. Is the Quebec provincia administrative database a valid source for research on chronic noncancer pain? Pharmacoepidemiol Drug Saf 2015;24:980-90.

63 Clarke H, Soneji N, Ko DT, et al. Rates and risk factors for prolonged opioid use after major surgery: population based cohort study. BMJ 2014;348:g1251

64 College of Pharmacists of British Columbia. New safety measures for codeine liquid preparations coming soon. Victoria, BC, 2019.

65 Liu Y, Logan JE, Paulozzi LJ, et al. Potential misuse and inappropriate prescription practices involving opioid analgesics. Am J Manag Care 2013;19:648-58.

66 Kantor ED, Rehm CD, Haas JS, et al. Trends in prescription drug use among adults in the United States from 1999-2012. JAMA 2015;314:1818-31.

67 College of Pharmacists of British Columbia. Controlled prescription program. Vol. 2018.3. Vancouver, BC, 2018.

68 Schultz SE, Glazier RH. Identification of physicians providing comprehensive primary care in Ontario: a retrospective analysis using linked administrative data. CMAJ Open 2017;5:E856-63. 